\title{
Incentives and limitations of Greek blood donors: Application of the Health Belief Model in the design of recruiting strategies.
}

\author{
Christina Sereti ${ }^{1}$, Ioanna Apostolidou ${ }^{1}$, Maria Baka ${ }^{1}$, Nikolaos Koutsoubos $^{2}$, Aristeidis Seretis ${ }^{3}$, Maria Theodoratou $^{4}$ \\ 1 Blood Service, Thriasio General Hospital of Elefsis, Attica, Greece, 2 Department of Pathology, Thriasio General Hospital of Elefsis, Attica, Greece, 3 \\ Department of Hygiene and Epidemiology, University of Ioannina, Greece, ${ }^{4}$ Hellenic Open University, Neapolis University of Pafos, Cyprus \\ Keywords: k6 scale, motives, recruiting strategies, blood donation, health belief model \\ https://doi.org/10.52965/001c.24533
}

Health Psychology Research

Vol. 9, Issue 1, 2021

\section{Background}

Studies of the behavior of blood donors suggest that the examination of their incentives and reported barriers could be utilized in designing targeted recruiting strategies and awareness-raising campaigns.

\section{Methodology}

Data was collected via a questionnaire based on the Health Belief Model (HBM), aimed to examine reported incentives, limitations, benefits, and self-efficacy of 261 blood donors at Thriasio General Hospital from January 1 to March 1, 2020, after required permission provided. The analysis was performed by the use of the SPSS statistical software. In addition, a Greek translation of the K6+ distress scale was provided.

\section{Results}

Our sample consisted of 261 blood donors, the majority of which were men (88.5\%), 40-50 years old (36.4\%), high school graduates (49.4\%), and married (53.3\%). Heightened awareness of increased blood needs and blood shortages was mentioned. $92.8 \%$ of respondents believe that blood donation is an act of contribution to society or beneficial for their health (86.6\%). The limited working hours of blood donation services are the main obstacle mentioned by the participants (32.8\%), while $80.7 \%$ emphasized the need for public information campaigns. Based on the $\mathrm{K} 6$ scale answers score, most participants are classified in the intermediate-risk category for Serious Mental Illness (SMI).

\section{Conclusion}

The study of beliefs and incentives of blood donors is a critical factor in developing an effective recruiting strategy in a volunteering frame. Public information campaigns regarding the blood donation process and reminders aiming at the return of blood donors after the necessary time interval could facilitate this effort.

\section{INTRODUCTION}

Blood bank services are the central pillar of every health system, aiming to ensure the adequacy and safe distribution of necessary blood units to meet the needs of the patient, adopting updated clinical practice guidelines regarding the transfusion indications, the increased use of hematopoietic and hemostatic agents, and the preference of new, minimally invasive surgical techniques, aid to limit the excessive use of blood. ${ }^{1}$ On the other hand, the increase in life expectancy widens the demographic gap in favor of the older population, limiting the existing blood donor pool and creating additional blood needs. ${ }^{2}$

The design of an effective strategy to recruit blood donors without neglecting the importance of quality assurance in blood donation services requires the co-evaluation of both the socio-economic environment and human factors. Thus, the aim turns out to be double: maintaining the existing blood donor pool and recruiting new donors on a volunteer basis. Limitations to achieving this goal include the aging population and the establishment of strict blood donor selection criteria. 3,4

\footnotetext{
a Corresponding Author: Christina Sereti, Blood Donation Service of Thriasio General Hospital of Attica, G. Gennimata avenue, 19600, Magoula, Greece.

Email:xristinasereti@gmail.com
} 
A detailed study of demographic characteristics and attitudes, beliefs, and reported limiting and inhibitory factors of individual population subgroups is necessary before taking action. ${ }^{5}$ According to published medical literature, sociodemographic characteristics of blood donors, such as gender, age, and professional or educational status, affect their attitude towards blood donation. ${ }^{6}$ For example, a statistically significant correlation between family and occupational status, educational level, and blood donation frequency is found in several studies. ${ }^{7}$ Motivation could also be differentiated according to individual characteristics: although altruism seems to be the primary motive in published literature, the feeling of curiosity or the offer of noneconomic incentives may play an essential role in attracting specific population subgroups. 8,9 This research aimed to study blood donors' attitudes and beliefs and assess their psycho-emotional state during the 30 days before the blood donation procedure. Identifying the factors that motivate or discourage the act of blood donation has as its ultimate goal the design of "targeted" actions aiming to recruit new blood donors and promote volunteering, ensuring a permanent reservoir for the satisfaction of the blood needs of a specific region.

\section{THE HEALTH BELIEF MODEL}

The Health Belief Model (HBM) is a widely used research tool for human health behavior, highlighting established beliefs and proposing modifying behavioral interventions. Thus, its use in the blood donation research field could provide important information about blood donors' beliefs and attitudes. ${ }^{10-12}$

\section{STRUCTURAL COMPONENTS OF THE INITIAL DESCRIPTION OF THE HBM.}

In its original form, HBM is structured on four axes, which describe and predict the behavior and beliefs of the subject, serving as both an interpretive and modifying behavioral theoretical tool. ${ }^{13}$ The main components determining the behavioral framework of each subject are: perceived severity (beliefs about the seriousness of an illness and its possible effects if contracted), perceived susceptibility (the subjective sense of danger or risk about contracting a disease), perceived benefits (of a behavioral change, aiming at the depreciation of the first two structural components: reducing the likelihood of contracting a disease or treat its complications effectively) and perceived barriers (practical or psycho-emotional obstacles and limiting factors to the achievement of the final health-goal). ${ }^{14-16}$

The updated version of HBM, which has been widely used in literature, incorporates two new descriptive components aiming to increase its predictive power: self-efficacy (a concept introduced to describe the confidence of a person in his or her own ability to demonstrate behavior that will lead to the desired result) and cues to action (internal and external stimuli that can act as signals and trigger the subject to take a health action). ${ }^{17,18}$

\section{MATERIALS AND METHODS}

Quantitative research was selected to conduct the study to capture the trends of the population under investigation. The data collection technique used in the research is nonrandomized intentional sampling. Specifically, the nonrandomization of the sample lies in the fact that the main target is not the generalization due to the specific profile of the blood donors under study, as well as the fact that there are no conditions for the application of random sampling.

\section{STUDY INSTRUMENT}

The selection of the questionnaire questions was based on relevant international and Greek literature review: attention was paid to the simplicity, completeness, coherence, and succession of the questions to facilitate completion by the reader. The blood donation service staff reviewed the questionnaire content, and a pilot study took place on 50 blood donors. Recommendations from the service staff and blood donors resulted in modification of wording of items to improve readability and the addition of more "education" and "occupation" related categories, i.e., the selection "other" to include those answers that did not fall into any of the known categories. All questionnaires were handed back, and the internal consistency was adequate with a Cronbach's alpha value of 0.7 .

The questionnaire consisted of two parts. The first part included two sections: the first section consisted of 12 open-ended multiple-choice questions (regarding demographic, educational, and occupational characteristics of blood donors and the conditions/causes of blood donation in the past and present situations). The second section includes thirty-two (32) five-point Likert scale questions, where responders' level of agreement is specified by an ordered scale of five points/answers: (1) Strongly disagree, (2) Disagree, (3) Neither agree nor disagree, (4) Agree and (5) Strongly agree. ${ }^{19}$ These questions are further categorized into six (6) thematic axes in correspondence with the six structural components of the HBM, as previously described. The second part of the questionnaire consisted of the K6 (Kessler Psychological Distress) scale translated in Greek language and back-translated to detect possible ambiguities and confirm the accuracy of the initial translation, also in the form of a five-point Likert scale. K6 scale consists of a truncated version of the K10 scale, a 10-point psychometric tool for detecting non-specific psychological distress. Each question of the $\mathrm{K} 6$ scale can receive a score between 0 and 4, where " 0 " counts for "none of the time" and 4 for "all of the time" response. Thus, the total score, resulting from summing the six individual scores, ranges between 0 and 24 [20, 21]. This addition aims to assess the psychological state of blood donors during the last 30 days and reveal the existence of any possible depressive symptoms or psychological distress. ${ }^{20}$

\section{PARTICIPANTS}

The research was contracted at the Thriasio General Hospital of Elefsina, Greece, from January 1 to March 1, 2020. The blood donor sample included 261 participants, 30 of which 
were women and 231 were men, aging above 18 years old (36,4\% were between $40-50$ years old).

The criteria for admission to the research included candidates approved to donate blood, capable of consent, and comprehension of the Greek language. Donors incapable of reading or understanding the questionnaire content and candidates who were rejected from blood donation by the medical staff due to medical or other reasons were excluded from the study.

\section{SAMPLING AND DATA COLLECTION}

The recruitment method involved the voluntary completion of a questionnaire during the visit of the donor to the Thriasio General Hospital of Elefsina. On the day of attendance for blood donation, the study participants were given:

- An information form regarding the completion of the questionnaire

- A consent form

In addition, participants were informed about their ability to withdraw their personal data and their subsequent participation in the survey throughout its duration.

The initial number of questionnaires handed out was 270 , but 9 of them were only partially completed, providing a response rate of $96.6 \%$. Seventy-one candidates (61 men and 10 women) were disqualified from donating blood and were excluded from the study.

Data were collected from January 1 to March 1, 2020, via anonymous questionnaires, with written consent, as required by the General Data Protection Regulation (GDPR no.2016 / $679 \mathrm{EU})$, with the authorized permission under the number 428 of the Scientific Committee of Thriasio General Hospital of Attica. The distribution and completion of the questionnaires, which lasted about 10 minutes, took place after blood donation during the recovery time.

\section{QUESTIONNAIRE RELIABILITY}

A reliability analysis based on Cronbach's Alpha index was performed to test the internal consistency of the questionnaire. The Cronbach's Alpha Index provides information on how reliable a questionnaire is regarding several parameters of a questionnaire, scale, or test. Acceptable values range from 0.65 to 1 . In this research, the questions were divided according to the thematic categories described previously (sociodemographic characteristics, HBM based questionnaire, and K6 scale), and the reliability value was 0.714 , as appears in Table 1.

\section{LIMITATIONS}

This research was conducted in a randomized blood donor sample, including 231 men and 30 women. The number of female participants is significantly lower, reflecting the proportion of women blood donors in the general population. First-time donors were also few in number, and the attempted comparative analysis of their responses would likely vary if they constituted a more significant proportion of the sample.

The K6 scale interpretation was based on a cutoff point estimated by a calibration study corresponding to the U.S. population. Thus its value may not be optimal for our population.

Conduction of the survey coincided with the outbreak of the SARS-CoV-2 pandemic, an observation that should be taken into account during the analysis of the answers of the second part of the questionnaire, as it may be an additional source of stress.

It is also possible that some answers do not reflect the actual attitudes and beliefs of the participants but rather the "socially acceptable" response.

Finally, excluding those who donated blood but could not adequately understand or use the written Greek language also limits the possibility of generalization because such donors represent a high percentage of the local blood donors population.

\section{STATISTICAL ANALYSIS}

Data analysis was carried out through the Statistical Package for Social Sciences (SPSS) statistical software. Continuous variables were expressed with the mean value (mean), the deviation (deviation), and the standard deviation (sd). Then, conditions for parametric controls, such as regularity and homogeneity of dispersions, were studied. The significance level used for all tests was $\alpha=5 \%$. The Mann-Whitney $U$ test was performed to further examine differences in blood donor responses according to whether they have donated blood in the past. The Chi-Square test of independence was used to explore a statistically significant correlation between demographic and other personal variables in relation to various parameters of the respondents.

\section{RESULTS}

The present study sample consisted of 261 blood donors, the majority of which were men $(88.5 \%)$, while the women accounted only for $11.5 \%$. Most participants were $40-50$ years old (36.4\%), married (53.3\%), high school graduates (49.4\%), and private employees (55.6\%). 53\% donated blood more than twice a year, while $54.2 \%$ owned a volunteer blood donor card (Table 2).

Table 3 demonstrates the independence of specific questions of the blood donors according to general demographics data. The existence of a statistically significant relationship between gender, age, marital status, employment, and working hours and various parameters that control perceptions of blood donation for respondents were therefore investigated. A statistically significant association between gender, age, marital status, employment, and working hours and the variables presented in Table 3 was found $(\mathrm{p}<$ 0.05).

A percentage of $35.7 \%$ and $22.9 \%$ of responders "strongly agreed" or "agreed" respectively that our country cannot meet its needs through voluntary donation, whereas $43.8 \%$ of participants reported feeling vulnerable to a possible shortage of blood supplies and $72.4 \%$ of them declared to be willing to donate blood voluntarily. $80.5 \%$ of the participants strongly agreed/agreed that a blood donation is an act of social contribution, whereas $69 \%$ strongly agreed that it is beneficial for their health. $24.6 \%$ of responders reported 
Table 1. Cronbach's Alpha Index of the questionnaire

\begin{tabular}{|c|c|}
\hline Questions about perceived severity & $\begin{array}{l}\text { Cronbach's } \\
\text { Alpha }\end{array}$ \\
\hline The need for blood in Greece has increased due to the increase in traffic accidents. & 0,748 \\
\hline The needs for blood in Greece are greater during the summer months. & 0,743 \\
\hline Greece imports blood from abroad to meet the needs of patients with Mediterranean anemia. & 0,746 \\
\hline Greece is one of the countries that cannot meet the needs for blood only through voluntary blood donation. & 0,746 \\
\hline Greece has one of the lowest rates of voluntary blood donors in the world, compared to developed countries. & 0,742 \\
\hline The need for blood in Greece has increased due to the increase in surgeries and transplants. & 0,749 \\
\hline \multicolumn{2}{|l|}{ Questions about perceived susceptibility } \\
\hline If I or someone of mine needed blood transfusions were hardly enough people to donate blood. & 0,745 \\
\hline A possible lack of blood supplies would endanger my life or the life of mine. & 0,752 \\
\hline Young people are not going to need blood. & 0,747 \\
\hline Only people with certain conditions, such as Mediterranean anemia, need blood. & 0,745 \\
\hline I will only give blood when one of my own people needs it. & 0,752 \\
\hline \multicolumn{2}{|l|}{ Questions about perceived benefits } \\
\hline When I give blood, I feel that I offer to society as a whole. & 0,753 \\
\hline When I give blood, I feel that I am doing well in my health. & 0,752 \\
\hline I give blood so that there is a deposit in case I or someone of mine needs it. & 0,744 \\
\hline I donate blood to be tested for communicable diseases (e.g., hepatitis, HIV) & 0,741 \\
\hline I give blood to get leave from my job. & 0,748 \\
\hline When I donate blood voluntarily, I have the right to have free medical examinations - check-ups. & 0,736 \\
\hline \multicolumn{2}{|l|}{ Questions about perceived barriers } \\
\hline I am afraid that frequent blood donation may negatively affect my health in the future. & 0,744 \\
\hline I'm afraid of needles and/or blood. & 0,746 \\
\hline After giving blood, I will be more prone to diseases and viruses. & 0,745 \\
\hline I'm afraid that during the blood donation, I may catch a contagious disease. & 0,739 \\
\hline I am afraid that during the blood donation, I may feel dizzy/faint. & 0,752 \\
\hline I do not have time to go and donate blood. & 0,751 \\
\hline The opening hours of blood donation services are limited and do not make it easier for me. & 0,751 \\
\hline $\begin{array}{l}\text { I am afraid that from the medical examination before or after the blood donation, I may find out that I have some } \\
\text { disease or health problem. }\end{array}$ & 0,748 \\
\hline \multicolumn{2}{|l|}{ Questions about cues to action } \\
\hline The reminder through SMS or email would encourage me to donate blood. & 0,744 \\
\hline It would encourage me to donate blood by watching related commercials on T.V. & 0,748 \\
\hline There must be financial incentives for someone to donate blood. & 0,750 \\
\hline There must be better information about the blood donation process to the general public. & 0,755 \\
\hline I would be encouraged to donate blood by having mobile blood donation crews near my home/work area. & 0,751 \\
\hline \multicolumn{2}{|l|}{ Questions about self-efficacy } \\
\hline I believe I can become a regular blood donor. & 0,753 \\
\hline I believe that I will be able to donate blood within the next six months. & 0,755 \\
\hline \multicolumn{2}{|l|}{ Questions about Kessler Psychological Distress Scale (K6+) } \\
\hline During the past 30 days, about how often did you feel nervous & 0,686 \\
\hline During the past 30 days, about how often did you feel hopeless & 0,679 \\
\hline During the past 30 days, about how often did you feel restless or fidgety & 0,603 \\
\hline During the past 30 days, about how often did you feel so depressed that nothing could cheer you up & 0,691 \\
\hline During the past 30 days, about how often did you feel that everything was an effort & 0,692 \\
\hline
\end{tabular}




\begin{tabular}{|l|c|}
\hline During the past 30 days, about how often did you feel worthless & 0,684 \\
\hline $\begin{array}{l}\text { Taking them altogether, did these feelings occur more often in the past } 30 \text { days than is usual for you, about the same } \\
\text { as usual, or less often than usual? }\end{array}$ & 0,682 \\
\hline $\begin{array}{l}\text { During the past } 30 \text { days, how many days out of } 30 \text { were you totally unable to work or carry out your normal } \\
\text { activities because of these feelings? }\end{array}$ & 0,681 \\
\hline $\begin{array}{l}\text { Not counting the days, you reported in response to Q3, how many days in the past 30 were you able to do only half } \\
\text { or less of what you would normally have been able to do because of these feelings? }\end{array}$ & 0,677 \\
\hline During the past 30 days, how many times did you see a doctor or other health professional about these feelings? & 0,661 \\
\hline During the past 30 days, how often have physical health problems been the main cause of these feelings? & 0,694 \\
\hline
\end{tabular}

Table 2. Sociodemographic Characteristics of Participants

\begin{tabular}{|c|c|c|c|c|c|}
\hline \multirow[t]{2}{*}{ Baseline characteristic } & \multicolumn{2}{|c|}{ Full sample } & \multirow[t]{2}{*}{ Baseline characteristic } & \multicolumn{2}{|c|}{ Full sample } \\
\hline & $N$ & $\%$ & & $\mathbf{N}$ & $\%$ \\
\hline Gender & & & Working hours & & \\
\hline Female & 30 & 11.5 & Full time & 239 & 96.8 \\
\hline Male & 231 & 88.5 & Part-time & 8 & 3.2 \\
\hline Age & & & Previous blood donation & & \\
\hline $18-30$ & 59 & 22.6 & Yes & 243 & 93.1 \\
\hline $30-40$ & 82 & 31.4 & No & 18 & 6.9 \\
\hline $40-50$ & 95 & 36.4 & If yes, the frequency of blood donation & & \\
\hline$>50$ & 25 & 9.6 & Systematically (> 2 times a year) & 132 & 53 \\
\hline Marital status & & & Occasionally & 117 & 47 \\
\hline Single & 105 & 40.2 & How many years have you been a blood donor? & & \\
\hline Married/partnered & 139 & 53.3 & For first time & 16 & 6.1 \\
\hline Divorced & 15 & 5.7 & $1-5$ years & 73 & 28 \\
\hline Widowed & 2 & 0.8 & $>5$ years & 63 & 24.1 \\
\hline Educational level & & & $>10$ years & 109 & 41.8 \\
\hline $\begin{array}{l}\text { Elementary school } \\
\text { graduate }\end{array}$ & 9 & 0.8 & Reason for first blood donation & & \\
\hline $\begin{array}{l}\text { Junior high school } \\
\text { graduate }\end{array}$ & 23 & 8.8 & For a patient & 121 & 46.4 \\
\hline High school graduate & 129 & 49.4 & $\begin{array}{l}\text { Voluntary (participation in organized blood } \\
\text { donation outside the hospital) }\end{array}$ & 62 & 23.8 \\
\hline $\begin{array}{l}\text { University or } \\
\text { postgraduate degree }\end{array}$ & 99 & 37.9 & Voluntary (in a hospital) & 78 & 29.9 \\
\hline Other & 1 & 0.4 & Reason for today blood donation & & \\
\hline Employment & & & For a patient & 140 & 53.8 \\
\hline Unemployed & 5 & 1.9 & Voluntary & 120 & 46.2 \\
\hline Student & 11 & 4.2 & Owner of volunteer blood donor card & & \\
\hline $\begin{array}{l}\text { Employed in public } \\
\text { sector }\end{array}$ & 45 & 17.2 & Yes & 141 & 54.2 \\
\hline $\begin{array}{l}\text { Employed in private } \\
\text { sector }\end{array}$ & 145 & 55.6 & No & 119 & 45.8 \\
\hline Self-employed & 34 & 13.0 & & & \\
\hline Household & 3 & 1.1 & & & \\
\hline Other & 18 & 6.9 & & & \\
\hline
\end{tabular}

Note. $\mathrm{N}=261$ in total

that they donate blood to be tested for sexually transmitted diseases, whereas $81 \%$ disapproved of possible financial compensation for their actions.
The most frequently mentioned limiting factor was the limited working hours of blood donation service (15.4\% and $17.4 \%$ of participants "strongly agreed" and "agreed" re- 
Table 3.Results of independence test of specific questions of the blood donors in accordance with general demographics

\begin{tabular}{|c|c|c|}
\hline \multirow[t]{2}{*}{ Variables } & Statistical significance & Effect size \\
\hline & $P$-value & Phi/Cramer's V \\
\hline \multicolumn{3}{|l|}{ Sex } \\
\hline Have you donated blood in the past? & .04 & .14 (Small to moderate) \\
\hline Frequency of blood donation? & .84 & \\
\hline How many years have you been a blood donor? & .03 & .16 (Small to moderate) \\
\hline Reason for donating blood for the first time? & .31 & \\
\hline Reason for today's blood donation? & .44 & \\
\hline Do you have a volunteer blood donor card? & .70 & \\
\hline \multicolumn{3}{|l|}{ Age } \\
\hline Have you donated blood in the past? & .00 & .25 (Medium to large) \\
\hline Frequency of blood donation? & .28 & \\
\hline How many years have you been a blood donor? & .00 & .35 (Large) \\
\hline Reason for donating blood for the first time? & .65 & \\
\hline Reason for today's blood donation? & .02 & .17 (Small to moderate) \\
\hline Do you have a volunteer blood donor card? & .00 & .24 (Medium to large) \\
\hline \multicolumn{3}{|l|}{ Marital status } \\
\hline Have you donated blood in the past? & .13 & \\
\hline Frequency of blood donation? & .04 & .16 (Small to moderate) \\
\hline How many years have you been a blood donor? & .00 & .19 (Medium to large) \\
\hline Reason for donating blood for the first time? & .09 & \\
\hline Reason for today's blood donation? & .48 & \\
\hline Do you have a volunteer blood donor card? & .43 & \\
\hline \multicolumn{3}{|l|}{ Educational level } \\
\hline Have you donated blood in the past? & .20 & \\
\hline Frequency of blood donation? & .82 & \\
\hline How many years have you been a blood donor? & .53 & \\
\hline Reason for donating blood for the first time? & .31 & \\
\hline Reason for today's blood donation? & .94 & \\
\hline Do you have a volunteer blood donor card? & .83 & \\
\hline \multicolumn{3}{|l|}{ Employment status } \\
\hline Have you donated blood in the past? & .08 & \\
\hline Frequency of blood donation? & .46 & \\
\hline How many years have you been a blood donor? & .01 & .17 (Medium to large) \\
\hline Reason for donating blood for the first time? & .44 & \\
\hline Reason for today's blood donation? & .02 & .17 (Small to moderate) \\
\hline Do you have a volunteer blood donor card? & .28 & \\
\hline \multicolumn{3}{|l|}{ Daily working hours } \\
\hline Have you donated blood in the past? & .09 & \\
\hline Frequency of blood donation? & .71 & \\
\hline How many years have you been a blood donor? & .09 & \\
\hline Reason for donating blood for the first time? & .68 & \\
\hline Reason for today's blood donation? & .19 & \\
\hline Do you have a volunteer blood donor card? & .33 & \\
\hline
\end{tabular}


spectively) rather than the available/free time of participants (rates $3.9 \%$ and $7.8 \%$, respectively). It is also noteworthy that a significant percentage of blood donors strongly agreed $(5.4 \%)$ or agreed $(7.7 \%)$ that they were concerned about the possibility that the donation-related medical check-up may reveal the existence of a health problem. Finally, the fear of adverse events during donation was also reported with high frequency (1.5\% and $13.9 \%)$. A smaller percentage of blood donors reported phobia at the sight of blood or needles (4.6\% and $6.2 \%$, respectively). The results of the Kruskal $\mathrm{H}$ test are presented in Table 4, where the primary variable was the "years of blood donation" of the participants, and to what extent the various responses differentiate in statistically significant terms. For instance, first-time blood donors seemed to be less familiar with the increased needs of Greece for voluntary blood donation ( mean first time $=2.93$ vs. mean $>10$ years $=3.98$ ).

The following section estimated the "signals to action," revealing that a large percentage of participants actually could be mobilized by personal reminders or media adverts (54.6\%), as presented in Table 4. Financial incentives were not considered important by most blood donors (81\%), but an equally large percentage $(80.7 \%)$ underlined the need for public information campaigns about the blood donation process.

Self-efficacy was examined in the last two responses of the first part of the questionnaire. A significant percentage of blood donors believe that they can become regular donors and return to the blood donation services within the next six months (67.2\% and 68.9\% "agreed," respectively).

The application of the $\mathrm{K} 6$ distress scale revealed that a significant percentage of blood donors had been feeling anxious all (5.3\%) or most of the time (15.6\%) during the last 30 days, while a consistently small percentage $(3.7 \%$ $6.6 \%$ ) indicated the presence of symptoms that may show some type of depressive disorder. Only 30 participants reported visiting a doctor or other specialist for these feelings. Among blood donors who saw a specialist, 11 were volunteers, whereas 19 donated blood for a specific patient, an observation that may indicate an additional stress source.

Our study's total K6 scale mean score was 5.04 but varied significantly according to sex (mean score 6.6 and 4.85 for women and men, respectively). The presentation of the $\mathrm{K} 6$ scale answers and their further classification can be performed in two ways, as previously described ${ }^{20}$ Based on the first approach, a cutoff point of 13 discriminates populations at low or high risk of Serious Mental Illness (SMI). In our study, 17 participants (12 men and 5 women, i.e., 5.5\% and $17.5 \%$ respectively) had a score equal to or higher than 13 , indicating the increased possibility of SMI presence. The second approach classifies participants into four categories of no, low, moderate, or high risk of SMI, according to their score $\left(0,1-5,6-10\right.$, and $11-24$, respectively). ${ }^{21}$ The majority of participants were classified in the low-risk category, i.e., 123 men and 15 women (that account for $53.25 \%$ and $50 \%$ of total men and women respectively), though the ones of high risk counted for $9.2 \%$ and $21.4 \%$ of total men and women respectively (Table 5).

\section{DISCUSSION}

Participants' sociodemographic characteristics in this study were in accordance with those previously described in Greek literature: most blood donors were male, married, aged 40-50 years, high school graduates, and private employees. ${ }^{22}$ Minor differences, related mainly to professional status, were observed in agreement with the findings of Chlaoutakis et al., where students and military personnel were more than freelancers and university graduates, a difference that could be attributed to sampling selection and synthesis due to hospital region area characteristics. ${ }^{23}$ Differences in blood donors demographic characteristics patterns are not limited to Greece: in the study by Mohammed and Essel, a statistically significant correlation between family status, educational level, and blood donation frequency were found, while occupational and educational status were also related to the amount of knowledge about blood donation in the article by Shenga et al.,23 A recent study also found a higher probability for older, higher-educated, and financial-level men to be blood donors. ${ }^{24}$ Interestingly, a Greek study highlighted the significant lack of basic knowledge about blood donation in highly educated respondents, who reported the feeling of curiosity as the primary motivating factor for first-time blood donation. ${ }^{9}$

Altruism and the need for social contribution were reported to be the main incentives of blood donors in agreement with many previously published studies. ${ }^{25,26}$ Another widely recognized, albeit less dynamic, motive for voluntary blood donation is the feeling of social acceptance and recognition. ${ }^{27,28}$ Individuals belonging to minorities and specific racial groups (such as African-Americans and Latinos) are often motivated by the feeling that they are members of a larger group, assessing as significant the influence of their social environment. ${ }^{29}$

The type of motivation that influences the decision about blood donation has also been associated with several demographic characteristics: women seem to be more motivated by the need of helping their fellow human beings, being mainly influenced by their family environment, while men more often cite social pressure as the primary motive, responses that highlight the influence of social gender roles. ${ }^{30}$

Non-economic, contributory incentives are an essential incentive for many blood donors, differentiated according to age, educational level, gender, and ethnicity. ${ }^{30}$ In our research, these incentives included days off work due to blood donation and the right to conduct free medical examinations. A large percentage of blood donors (24.6\%) reported that the main reason they donate blood is to be tested for sexually transmitted diseases, a response that should be taken into account by the medical staff of blood donation, as it may undermine the safety and quality of blood units. Financial compensation for blood supply seemed to be rejected by the vast majority (81\%) of blood donors, agreeing with similar published studies. ${ }^{31}$

The classification of blood donors based on their sociodemographic characteristics highlights sub-groups re- 
Table 4. Mean and standard deviations for the questions referring to the years of blood donation compared to the following variables. Statistical significance test of the differences of the averages (Kruskal Wallis $\mathrm{H}$ Test) [x1]

\begin{tabular}{|c|c|c|c|c|c|c|c|c|c|c|c|}
\hline \multirow{3}{*}{$\begin{array}{l}\text { Years of blood } \\
\text { donation } \\
\text { Variables }\end{array}$} & \multicolumn{2}{|c|}{ First time } & \multicolumn{2}{|c|}{$1-5$ years } & \multicolumn{2}{|c|}{$>5$ years } & \multirow{2}{*}{\multicolumn{2}{|c|}{$>10$ years }} & \multirow{2}{*}{\multicolumn{3}{|c|}{$\begin{array}{l}\text { Statistical significance } \\
\text { results }\end{array}$}} \\
\hline & \multicolumn{6}{|c|}{ Measures } & & & & & \\
\hline & Mean & SD & Mean & SD & Mean & SD & Mean & SD & $\mathrm{H}$ & df & $p$ \\
\hline $\begin{array}{l}\text { The need for } \\
\text { blood in } \\
\text { Greece has } \\
\text { increased due } \\
\text { to the increase } \\
\text { in road } \\
\text { accidents. }\end{array}$ & 4.33 & 0.82 & 3.93 & 1.02 & 3.94 & 0.98 & 4.27 & 0.87 & 8.528 & 3 & .04 \\
\hline $\begin{array}{l}\text { The needs for } \\
\text { blood in } \\
\text { Greece are } \\
\text { greater during } \\
\text { the summer } \\
\text { months. }\end{array}$ & 3.73 & 1.10 & 3.64 & 1.07 & 3.97 & 1.02 & 4.22 & 0.99 & 15.453 & 3 & .00 \\
\hline $\begin{array}{l}\text { Greece } \\
\text { imports blood } \\
\text { from abroad to } \\
\text { meet the } \\
\text { needs of } \\
\text { patients with } \\
\text { Mediterranean } \\
\text { anemia. }\end{array}$ & 3.14 & 1.10 & 3.28 & 0.98 & 3.36 & 1.02 & 3.74 & 1.13 & 11.105 & 3 & .01 \\
\hline $\begin{array}{l}\text { Greece is one } \\
\text { of the } \\
\text { countries that } \\
\text { cannot meet } \\
\text { the needs for } \\
\text { blood only } \\
\text { through } \\
\text { voluntary } \\
\text { blood } \\
\text { donation. }\end{array}$ & 2.93 & 1.44 & 3.64 & 1.03 & 3.67 & 1.05 & 3.98 & 1.27 & 13.942 & 3 & .00 \\
\hline $\begin{array}{l}\text { A possible lack } \\
\text { of blood } \\
\text { supplies would } \\
\text { endanger my } \\
\text { life or the lives } \\
\text { of mine. }\end{array}$ & 4.25 & 1.00 & 3.73 & 1.28 & 3.87 & 1.13 & 4.13 & 1.22 & 8.589 & 3 & .03 \\
\hline $\begin{array}{l}\text { When I give } \\
\text { blood, I feel } \\
\text { that I am doing } \\
\text { good for my } \\
\text { health. }\end{array}$ & 4.63 & 1.02 & 4.47 & 0.87 & 4.30 & 0.93 & 4.64 & 0.76 & 9.996 & 3 & .02 \\
\hline $\begin{array}{l}\text { After giving } \\
\text { blood, I will be } \\
\text { more prone to } \\
\text { diseases and } \\
\text { viruses. }\end{array}$ & 1.81 & 1.05 & 1.77 & 1.05 & 1.51 & 0.93 & 1.50 & 1.15 & 9.234 & 3 & .03 \\
\hline $\begin{array}{l}\text { I do not have } \\
\text { time to go and } \\
\text { donate blood. }\end{array}$ & 1.94 & 1.00 & 2.00 & 1.12 & 1.55 & 1.00 & 1.82 & 1.29 & 8.215 & 3 & .04 \\
\hline $\begin{array}{l}\text { The reminder } \\
\text { via SMS or } \\
\text { email would } \\
\text { encourage me } \\
\text { to donate } \\
\text { blood. }\end{array}$ & 3.19 & 1.38 & 3.16 & 1.38 & 3.57 & 1.41 & 3.77 & 1.44 & 10.999 & 3 & .01 \\
\hline $\begin{array}{l}\text { It would } \\
\text { encourage me } \\
\text { to donate }\end{array}$ & 3.56 & 1.09 & 3.15 & 1.36 & 3.57 & 1.28 & 3.72 & 1.33 & 9.567 & 3 & .02 \\
\hline
\end{tabular}




\begin{tabular}{|l|l|l|l|l|l|l|l|l|l|l|l|}
\hline $\begin{array}{l}\text { blood by } \\
\text { watching } \\
\text { related } \\
\text { commercials } \\
\text { on T.V. }\end{array}$ & & & & & & & & & & & \\
\hline $\begin{array}{l}\text { There needs to } \\
\text { be better } \\
\text { information } \\
\text { about the } \\
\text { blood } \\
\text { donation } \\
\text { process to the } \\
\text { general public. }\end{array}$ & 3.63 & 1.20 & 4.04 & 1.03 & 4.19 & 0.99 & 4.54 & 0.86 & 22.598 & 3 & .00 \\
\hline $\begin{array}{l}\text { I would be } \\
\text { encouraged to } \\
\text { donate blood } \\
\text { by having } \\
\text { mobile blood } \\
\text { donation } \\
\text { crews near my } \\
\text { home/working } \\
\text { area. }\end{array}$ & 3.63 & 1.20 & 3.59 & 1.22 & 3.79 & 1.17 & 4.06 & 1.17 & 9.682 & 3 & .02 \\
\hline $\begin{array}{l}\text { I believe I can } \\
\text { become a } \\
\text { regular blood } \\
\text { donor. }\end{array}$ & 3.75 & 1.18 & 4.29 & 1.05 & 4.39 & 0.96 & 4.71 & 0.68 & 23.313 & 3 & .00 \\
\hline $\begin{array}{l}\text { I believe that I } \\
\text { will be able to } \\
\text { donate blood } \\
\text { within the next } \\
\text { six months. }\end{array}$ & 3.88 & 1.31 & 4.39 & 0.93 & 4.52 & 0.90 & 4.68 & 0.73 & 14.928 & 3 \\
\hline
\end{tabular}

Note. $\mathrm{x} 1$. This is a Non-Parametric test where the mean values $\mu 1, \mu 2, \mu 3, \ldots \mu \mathrm{k}$ of samples for $\mathrm{k}>2$ are compared.

Abbreviations: $\mathrm{SD}=$ standard deviation, $\mathrm{H}=$ the test statistic for the Kruskal Wallis test, $\mathrm{df}=$ degrees of freedom, $\mathrm{p}=\mathrm{p}$-value

Table 5. K6 scale answers

\begin{tabular}{|c|c|c|c|c|c|c|c|c|}
\hline \multirow[t]{2}{*}{ Sex } & \multicolumn{2}{|c|}{0 (No risk) } & \multicolumn{2}{|c|}{ 1-5 (Low risk) } & \multicolumn{2}{|c|}{ 6-10 (Moderate risk) } & \multicolumn{2}{|c|}{ 11-24 (High risk) } \\
\hline & $N$ & $\%$ & $N$ & $\%$ & $N$ & $\%$ & $N$ & $\%$ \\
\hline Men & 21 & 9.6 & 123 & 56.7 & 53 & 24.4 & 20 & 9.2 \\
\hline Women & 1 & 3.5 & 15 & 53.6 & 6 & 24.1 & 6 & 21.4 \\
\hline
\end{tabular}

Note. $\mathrm{N}$ men total $=217, \mathrm{~N}$ women total $=28$

ceptive to different approaches. Age is a typical example. According to the study of Glynn et al., younger people were more receptive to the offer of non-financial, contributory incentives than older people, a finding also confirmed by research conducted in 2018 at American and German colleges. 8,32 Similarly, financial compensation has also been differently estimated depending on the gender, with women participants recording higher disapproval rates. ${ }^{31}$ Our study did not reveal any significant association between gender, age, education, and the approval of contributory incentives. Still, it is noteworthy that a substantial percentage of private employees evaluated positively both the offer of economic incentives and the days off work.

Motives that relate to the first blood donation experience are not dictated by the need to satisfy altruistic needs but stem from the influence of the immediate social, family, and friendly environment. ${ }^{25}$ Indeed, of the 18 first-time donors, 11 (61.1\%) replied that they donated blood for a patient. As shown by studies of Mohammed and Screiber et al., the quality of blood donation services, related both to staff training and blood donation environment setting, is a decisive factor for the return of blood donors. ${ }^{7,33}$

In our study, the main reported limitation was the working hours of blood service. The most commonly reported inhibiting factors in the literature include the possibility of adverse events and fear at the sight of blood or needle, followed by the concern that blood donation is a painful experience, limited available free time or long distance to the blood donation service, reservations about the health system and blood disposal transparency, the long duration of the procedure, and the inadequate evaluation of blood donation services in general. ${ }^{30,34}$ The difference in the hierarchy of inhibitory factors observed in the present study is due to the sample population: donors who are approved are 
less likely to be afraid of needles and/or blood and adverse reactions than those who are eventually rejected. Application of the questionnaire to the general population would probably result in a revision of the hierarchy of responses in this thematic section.

As per previous studies, in which HBM was applied to examine blood donors' beliefs and attitudes, the importance of self-efficacy for the repeatability of the blood donation act was highlighted. In the study of Lu et al., self-efficacy appeared to be a primary predictor of blood donation intention, and the same conclusion was also met in the study of Masser et al. ${ }^{11,12}$ Armitage and Conner also attributed to self-efficacy a more significant predictive capacity of the subject's intentions compared to the sense of control, suggesting a clear distinction between these two factors. 35,36

The second part of the questionnaire, which examines aspects of the psycho-emotional blood donor state, revealed that a small but stable percentage of responders exhibited symptoms of possible anxiety or depressive disorder, which should be assessed with additional questions during the donor interview by medical staff. A primary criterion for selecting blood donors is their physical and psychological health since anti-depressant treatment is a cause of exclusion. Therefore, the presence of eligible blood donors that were simultaneously receiving pharmaceutical treatment raises suspicions about the sincerity of their answers in general. The emotional state has also been associated with a higher percentage of adverse events during the blood donation, as the process itself acts as an additional stressful factor and its outcome depends on the stress management technique that each person employs. ${ }^{37}$

\section{CONCLUSION AND FURTHER PROPOSALS}

The growing needs in blood and its products make it imperative to develop effective blood donor recruiting strategies. Understanding the motives of blood donors constitutes a key objective, as they may differ according to donation frequency and type. The transformation of social influence that directs the first blood experience into altruistic behavior, that guarantees its continuation, requires the development of appropriate strategies, presenting the act of blood donation as an "ideal," desirable, and socially responsible behavior. Implementation of public information campaigns and organization of external blood donations to educational institutions have multiple objectives: on the one hand, they are false beliefs and phobias reconstructive tools and means of behavior modification, and on the other hand, they facilitate direct communication with the medical and nursing staff, an interaction that could improve the quality of the provided services.

Knowledge about the specific needs of certain subgroups of patients, which can be acquired either by direct patient contact or by social and humanitarian courses in school life, can be a pillar of awareness and substantial support for these categories of patients in various ways. The development of strategies aiming to stimulate and strengthen the spirit of volunteering could both appease the fear and insecurity of patients and their relatives and guarantee the safe and smooth operation of blood donation services.

The concept of self-efficacy, which is a crucial structural component of Health Psychology and perhaps the determining predictor of the subject's intention to act, can be enhanced by targeted interventions, depending on the blood donation history of each person. ${ }^{36}$ Focus on the process of blood donation itself, and reassuring techniques enhance the feeling of self-efficacy of first-time blood donors. In contrast, service quality and efficiency improvement play a more important role in regular blood donors. 38

Finally, the contribution of reminders to patient compliance, which has been observed in several studies, is also important in recruiting and retaining blood donors. However, there is no precise data about their long-term effectiveness. ${ }^{5}$

\section{ACKNOWLEDGMENTS}

We thank the blood donors of Thriasio General Hospital for taking part in our study and the staff working in the blood collection department for their kind contribution.

\section{AUTHOR CONTRIBUTIONS}

All the listed authors contributed equally to the design and implementation of the research, data collection, and resulting analysis. All the authors critically read and revised the final manuscript and agree to be accountable for all aspects of the work in ensuring that questions related to the accuracy or integrity of any part of the work are appropriately investigated and resolved.

\section{CONFLICTS OF INTEREST}

Authors have no conflicts of interest to declare.

\section{FUNDING STATEMENT}

This research received no funding.

Submitted: June 02, 2021 EST, Accepted: June 03, 2021 EST 


\section{REFERENCES}

1. Patel EU, Bloch EM, Grabowski MK, et al. Sociodemographic and behavioral characteristics associated with blood donation in the United States: a population - based study. Transfusion. 2019;59(9). do i:10.1111/trf.15415

2. Greinacher A, Fendrich K, Alpen U, Hoffmann W. Impact of demographic changes on the blood supply: Mecklenburg-West Pomerania as a model region for Europe. Transfusion. 2007;47(3):395-401. doi:10.111 1/j.1537-2995.2007.01129.x

3. Lee CK, Hong J, Hung ATF. An update of blood donor recruitment and retention in Hong Kong. Asian J Transfus Sci. 2008;2(2):47-50. doi:10.4103/0973-624 $\underline{7.42691}$

4. Misje AH, Bosnes V, Heier HE. Recruiting and retaining young people as voluntary blood donors. Vox Sang. 2008;94(2):119-124. doi:10.1111/j.1423-041 $\underline{0.2007 .01004 . \mathrm{x}}$

5. Ferguson E, France CR, Abraham C, Ditto B, Sheeran $\mathrm{P}$. Improving blood donor recruitment and retention: Integrating theoretical advances from social and behavioral science research agendas. Transfusion. 2007;47:1999-2010. doi:10.1111/j.1537-2 995.2007.01423.x

6. Shaz BH, James AB, Hillyer KL, Schreiber GB, Hillyer CD. Demographic Patterns of Blood Donors and Donations in a Large Metropolitan Area. Journal of the National Medical Association. 2011;103(4):351-357. doi:10.1016/s0027-9684(15)303 $\underline{16-3}$

7. Mohammed S, Essel HB. Motivational factors for blood donation, potential barriers, and knowledge about blood donation in first-time and repeat blood donors. BMC Hematol. 2018;18(1):36. doi:10.1186/s12 878-018-0130-3

8. Glynn SA, Williams AE, Nass CC, et al. Attitudes toward blood donation incentives in the United States: Implications for donor recruitment. Transfusion. 2003;43(1):7-16. doi:10.1046/j.1537-299 $\underline{5.2003 .00252 . x}$

9. Kalargirou AA, Beloukas AI. Attitudes and behaviours of Greeks concerning blood donation: Recruitment and retention campaigns should be focused on need rather than altruism. Blood Transfus. 2014;12:1-10. doi:10.2450/2014.0203-13
10. Ferguson E. Predictors of future behaviour: A review of the psychological literature on blood donation. Br J Health Psychol. 1996;1(4):287-308. do $\mathrm{i}: 10.1111 / \mathrm{j} .2044-8287.1996 . t b 00510 . \mathrm{x}$

11. Lu JE. Predicting Blood Donations Among College Students as a Strategy to Design Voluntary Blood Donation Campaigns in China. Florida State University; 2010. http://purl.flvc.org/fsu/fd/FSU_mig retd-1018

12. Masser BM, White KM, Hamilton K, McKimmie BM. An examination of the predictors of blood donors' intentions to donate during two phases of an avian influenza outbreak. Transfusion. 2010;51:548-557. doi:10.1111/j.1537-2995.2010.0288 7.x

13. Abraham C, Sheeran P. The Health Belief Model. In: Cambridge Handbook of Psychology, Health and Medicine. 2nd ed. Cambridge University Press; 2005:97-102. https://doi.org/10.1017/cbo9780511543 $\underline{579.022}$

14. Carter S, Garfied S, Newbould J, et al. A Review of the Use of the Health Belief Model (HBM), the Theory of Reasoned Action (TRA), the Theory of Planned Behaviour (TPB) and the Trans-Theoretical Model (TTM) to Study and Predict Health-Related Behaviour Change.; 2006.

15. Champion VL, Skinner CS. The Health Belief Model Health Behavior and Health Education: Theory, Research, and Practice. 4th ed. Jossey-Bass; 2008:45-65.

16. Jones CL, Jensen JD, Scherr CL, Brown NR, Christy $\mathrm{K}$, Weaver J. The Health Belief Model as an explanatory framework in communication research: exploring parallel, serial, and moderated mediation. Health Commun. 2015;30(6):566-576. doi:10.1080/104 $\underline{10236.2013 .873363}$

17. Bandura A. Self-efficacy: toward a unifying theory of behavioral change. Psychol Rev. 1977;84(2):191-215. doi:10.1037/0033-295x.84.2.191

18. Janz NK, Becker MH. The Health Belief Model: A decade later. Health Educ Q. 1984;11(1):1-47. doi:10.1 177/109019818401100101

19. Likert R. A technique for the measurement of attitudes. Archives of Psychology. 1932;22 140:55-55. 
20. Kessler RC, Barker PR, Colpe LJ, et al. Screening for serious mental illness in the general population. Arch Gen Psychiatry. 2003;60(2):184-189. doi:10.1001/ archpsyc.60.2.184

21. Muhuri PK. Serious Psychological Distress and Mortality among Adults in the U.S. Household Population: Highlights. The CBHSQ Report. Substance Abuse and Mental Health Services Administration (U.S.); 2013:1-6.

22. Ioannidou M. Investigation of blood donors attitudes, behaviour and level of knowledge towards blood donation. Published online 2009. http://hdl.han dle.net/10442/hedi/26857

23. Pal R, Shenga N, Thankappan K, Kartha C. Analyzing sociodemographic factors amongst blood donors. J Emerg Trauma Shock. 2010;3(1):21-25. doi:1 $\underline{0.4103 / 0974-2700.58667}$

24. Zucoloto ML, Gonçalez T, Custer B, McFarland W, Martinez EZ. Comparison of the demographic and social profile of blood donors and nondonors in Brazil. Health Soc Care Community. 2019;27(2):330-336. doi:10.1111/hsc. 12650

25. Sojka BN, Sojka P. The Blood Donation Experience: Self-Reported Motives and Obstacles for Donating Blood. Vox Sang. 2008;94:56-63. doi:10.111 1/j.1423-0410.2007.00990.x

26. Steele WR, Schreiber GB, Guiltinan A, et al. The role of altruistic behavior, empathetic concern, and social responsibility motivation in blood donation behavior. Transfusion. 2007;48(1):43-54. doi:10.1111/ j.1537-2995.2007.01481.X

27. Chell K, Mortimer G. Investigating online recognition for blood donor retention: An experiential donor value approach. Int J Nonprofit Volunt Sect Mark. 2014;19(2):143-163. doi:10.1002/nv $\underline{\text { sm. } 1489}$

28. Theodoratou-Bekou M. Psychological maturing and coping strategies: study based on group process. Groupwork. 2008;18(1):76-98. doi:10.1921/19657

29. Finck R, Ziman A, Hoffman M, Phan-Tang M, Yuan S. Motivating Factors and Potential Deterrents to Blood Donation in High School Aged Blood Donors. J Blood Transfus. Published online 2016. doi:10.1155/2 $\underline{016 / 8624230}$
30. Yuan S, Hoffman M, Lu Q, Goldfinger D, Ziman A. Motivating factors and deterrents for blood donation among donors at a university campus-based collection center. Transfusion. 2011;51:2438-2444. do i:10.1111/j.1537-2995.2011.03174.x

31. Mellström C, Johannesson M. Crowding out in blood donation: Was Titmuss right? Journal of the European Economic Association. 2008;6(4):845-863. do i:10.1162/jeea.2008.6.4.845

32. Sadler A, Shi L, Bethge S, Mühlbacher A. Incentives for Blood Donation: A Discrete Choice Experiment to Analyze Extrinsic Motivation. Transfus Med Hemother. 2018;45. doi:10.1159/000481142

33. Schreiber GB, Schlumpf KS, Glynn SA, et al. Convenience, the Bane of our Existence, and Other Barriers to Donating. Transfusion. 2006;46(4):545-553. doi:10.1111/j.1537-2995.2006.00 757.x

34. Hupfer ME, Taylor DW, Letwin JA. Understanding Canadian student motivations and beliefs about giving blood. Transfusion. 2005;45:149-161. doi:10.11 11/j.1537-2995.2004.03374.x

35. Armitage CJ, Conner M. Social Cognitive Determinants of Blood Donation. J Appl Social Pyschol. 2006;31:1431-1457. doi:10.1111/j.1559-181 6.2001.tb02681.x

36. Giles M. An application of the Theory of Planned Behaviour to blood donation: the importance of selfefficacy. Health Education Research. 2004;19(4):380-391. doi:10.1093/her/cyg063

37. Hoogerwerf MD, Veldhuizen IJT, Kort W, FringsDresen M, Sluiter JK. Factors associated with psychological and physiological stress reactions to blood donation: A systematic review of the literature. Blood Transfus. 2015;13:1-9. doi:10.2450/2015.0139-1 $\underline{4}$

38. Boulware LE, Ratner LE, Ness PM, et al. The Contribution of Sociodemographic, Medical, and Attitudinal Factors to Blood Donation among the General Public. Transfusion. 2002;42:669-678. doi:1 0.1046/j.1537-2995.2002.00120.x 